\title{
Analysis of Prediction Profit Announcement for Share to Volume of Share Transaction in Tehran Stock
}

\section{Exchange}

\author{
Reza Pirayesh \\ Faculty of Accounting and Management \\ University of Zanjan, Zanjan Iran \\ Tel: 98-912-141-2560 E-mail: r_pirayesh@yahoo.com, \\ Mahdi Salehi (Corresponding author) \\ Faculty of Accounting and Management \\ University of Zanjan, Zanjan, Iran \\ Tel: 98-912-142-5323 E-mail:mahdi_salehi54@yahoo.com \\ Ali Mansoury \\ Faculty of Accounting and Management \\ University of Zanjan, Zanjan, Iran \\ Tel: 98-912-346-9105Ｅ-mail:ali-mansory@yahoo.com
}

\begin{abstract}
There are some signs, considered as influencing factors on shares transaction volume in an investment market come in a form of information and various predictions are available for investors and other users. In this research, the effective information in the predicated dividend of each share which is issued by companies in Tehran Stock Exchange. Researches aim creates direction the shareholders and investors' decision-making process upon buying and holding the shares. In this propose doing, 78 companies among legitimate companies in Tehran Stock Exchange by using systematic omission method have chosen. This research has been done at the time of 2005 to 2007.

Result gained from Vilcakson Calibrated grades tests showed transaction volume in the weeks before and after the announcing the estimated profit of each share contains information content for which the investors and shareholders changed accordingly. In the other words, this announcement is considered highly valid and reliable among investors and shareholders. They rely on this information and make their decisions upon it.
\end{abstract}

Keywords: Estimated profit of each share, Real profit of each share, Shares transaction volume, Information content, Tehran stock exchange 


\section{Introduction}

Nowadays, timely and useful informing is the main basis for decision-making process preparing in information development world is one of the inevitable necessities in the different fields. In financial decision-making process, the investors intend their funds into the different field of economic.

Catch expected profit and come form economic dynamics of society. Tehran Stock Exchange (TSE) and its increasing activities can be a reason for the economic development. The profitability of a company is the most considerable criterion to the investors. The previous profit reflects the information regarding the past, so that, we can rely on this information to assess the company's past performance. If the investors consider the past performance of the company as their main factors, they can guess how the future will be hosed upon the company's record in the past. Of course, this guess is partly unreliable, because the future certainly is different from the past. So the information regarding the future is relatively reliable. Hence, the prediction of the future activities of the company plays a critical role in the optimal decision-making process by investors.

The future revenue of the companies and the predicted profit of each share depend upon the managers' policies regarding measure of product sale, marketing and other strategic decisions. Hence, any announcement by the management entails a message for the investors and if they consider the message as a reliable message, there will be a change in their attitudes and opinions. So that they can optimize their decisions, this attitude can lead to change in supply and demand for the stocks (shares) as well as transactions volume. In short, this research tries to consider the change in the rate and volume of shares (stocks) transaction regarding the effectiveness or infectiveness of financial statements, especially the predicated profit of each share, by the companies' managers in TSE.

\section{Research Problem}

Basically, to buy of shares, the investors consider all of aspects thoroughly. Because, they convert their cash into the shares, so they consider all the dimensions, the results will be favorable.

There are many factors influence in decision selection. Also, financial market is a perfect environment to evaluate of investors behavior. There are important factors for the investors in issuing of companies reports. They are basically worried about the share price in the future. So, the most impressing subject for the investors is the information which helps them to plan for the future (Baker and Haslen, 1974, pp.476-469).

There are some signs and marks, considered as influencing factors on shares transaction volume in capital market, come in a form of internal information and various predictions and are available for investors and other users. It is supposed investors and considers these predictions as a reliable casts (JahanKhani, 2003, p. 68-63).

To get the information regarding the future profitability of company for the new decision-making, investors need a report (statement) which entails the necessary information 
for the company's profitability. In order to buy the shares, investors need to consider the shares' value prediction in the upcoming years.

Regarding most of profitable units, information related with profit predictions in compared with prediction of the dividend in the short run is supposed to predict the future price of the shares. So, investors use these expectations to predict the dividend distribution in the future, of course, dividend distribution is considered as a main factor in determining shares price or the overall of the profitable units (Shabahank, 2002, p.189). In the model of assessment profit units based upon dividend, the value of enterprise in view of shareholders equalize the profit unit value to the current value of the dividend to be received by them in the future. The current price of the shares is considered as a function of the expected dividend in the future. In other words, shares price is a function of the current value of the predicted earnings for the shares in the future (Binnr, 1998, pp. 38-46).

Hence, the predicted profit announced by the companies' managers can be considered highly reliable for users, especially the potential and real investors' behavior affected by them. Then investors can buy the shares the shareholders can decide over selling or holding their shares with announcement predicted profit. So, the rate and volume of the shares transaction can undergo changes based upon the estimated profit of each share and affect the user's behaviors.

\section{The goals of the research}

This research can be considered significant from different perspectives as follows:

1) Investors and shareholders can use the predicted profit of each share as a basis for their future decisions. In order to buying shares, the investors need to consider shares value prediction in the upcoming years. Obviously, the determination of this value is dependent upon the profitability of the companies in the future. In most of enterprises, the prediction of the dividend for the prediction of the market price of share is considered more important than the prediction of the divided distribution so, expected dividend plays a main role in pricing the current value of shares or the total value of enterprise. Based upon these expectations, a shareholder can decide over buying or holding his/her shares and a potential investor, also, decides over buying the company's shares.

2) The management's predictions regarding the profit of each share is considered highly valuable for the bond holders and short-term creditors and the reliability of existing content information can help them make financial decisions.

The bond holders and short-term creditors are interest regarding the future profit (divided). The prediction of more profit for the companies increases their confidence in receiving the annual return and repayment of the original credit Justin time.

The predictions by the companies' officials are considered as an important source and valid information about the future profit. Hence, investors can be assessed the reliability of the management's predictions about the profit based upon the past performance of the company.

In this research, the following goals are considered: 
1) The analysis of the estimated profit (dividend) for each share and the rate as well as the volume of transactions in the accepted companies in TSE.

2) Showing trace and evidence of information content in the predicted profit announcement for each share which is issued through TSE.

3) Endeavor to direct the investors and shareholders' decision-making process regarding buying, selling or holding in TSE.

\section{Review of Literature}

There are international and national researches which here are going to explain at first international research then the national researches.

\subsection{International literature}

The research carried out by Ball and Brown (1968) that paved the way for the other studies. It was about 261 companies during 1946-65; it considered the relationship between price and profit changes. They found out that the most considerable price reaction occurs before announcement of annual profit and just nearly $10 \%$ of the changes occur in the month in which announcement develops.

These results approve that prices reflect the expected profit. By Foster (1973) prepared an article that called the stock market reaction against the estimated profit of each share by the professional companies. He pointed out that based upon the volume and price consideration of the shares, both investors and the market estimation EPS before the auditing into account because of its information content and that time, the general estimation of the shares price quickly is adjusted.

The research by Patell (1976) In order to assess the information content regarding the profit prediction, he decided to test it through exposure the predicted profit on the shares price. The result showed that revealing the predictions leads to the adjustment in the shares price and the transactions volume. Hence, the predicted data entailed the information content.

The research by Baginski (1987); this research provides evidence regarding the effectiveness of information transfer with respect to the profit predicted by the management. This evidence supports this fact that the information entailed in management's prediction leads to the reaction he of the shares price.

The research conduct by Warneryd (2001) In order to get insight into the investor's financial decision-making and its relationship with the information developed in the financial markets, he considered the psychological and financial theories in details. He resulted that there is a concrete and clear relationship between the selection of financial investment and the investors' behavior regarding choosing the decisions.

A survey conduct by Wayman (2002); which he considered the profit earning as main goal behind the investment. He concluded that the profit ratio of per share have more influences on investors' decision-making. He recommended that the investors apply the profit of each share ratio in the financial decision-making process. 


\subsection{The researches carried out in Iran}

The research conducted by Amarloo (2001) regarding to the effect of the estimated ESP changes on the shares price in the accepted companies in TSE.

He concluded that the statement released by the management regarding the predicted profit can't transfer any information in the capital market.

The research carried out by Arabi (2000) with regard to the effect of estimated ESP adjustment on the shares price in the accepted companies TSE.

He claims that it is obvious that any information released by the management naturally entails a message. If this message proves reliable, it can change the investors' behavior and ideas. So they change and optimize their investment procedure.

Consequently, this causes a change in the supply and demand for the shares and their price. This research considers the shares market reaction and even the effect or lack of effect of the financial statement especially the prediction of each share profit by the accepted companies in TSE.

The research conducted by Heidary (2001) regarding to the analysis of shares transaction volume and the profit adjustment of each predicted profit in the accepted companies TSE.

The hypothesis behind this research is that: the profit adjustments of each predicted share can influence the transactions volume before the official announcement. Base upon the findings and the previous studies regarding TSE efficiency, it was shown that TSE is not efficient and information's used illegally by some of special people before it is released officially.

The research carried out by Mokhtarian (2004); which he considers influencing factors on the investors' decision-marking in TSE. He argues that there are 14 factors regarding the decision-making process such as predicted earning per share. He concluded that the investors don't trust the financial statements, financial ratios and the accounting system in general.

They stick importance to other factors like the shares price trends, the market condition and the recommendations source. The predicted profit for each share ranks fourth among the influencing factors on the decision-making process.

The research conducted by Mehran (2004) regarding to the relationship among the profit for each share, the dividend and the investment in the listed companies in TSE. His research contains 14 hypotheses. Two suppose in this research are as follows:

1) There is a meaningful relationship between the profit of each share and the predicted profit.

2) There is a meaningful relationship between the dividend of per share and the predicted profit. Ultimately, these estimates were confirmed based upon the data analysis.

The research by Abadi (2006) regarding to the effect of the estimated profit announcement on the shares (stocks) price in the accepted companies in TSE. He concludes that the predicted profit announcement of each share entails the information content to some extent and lead to 
a change in the shares price. However, based on the statistical tests, there is no meaningful difference between the average unusual earnings in the previous weeks and within week after the announcement. Hence, we can't certainly prove that the predicted profit of each share causes as a change in the shares price.

\section{The hypotheses of the Research}

Regarding the body of this survey the below hypotheses are assumed:

1) Announcement of the estimated profit of each share causes a change in the rate and volume of the shares transaction (stocks exchange).

2) There is a relationship between the estimated profit and the final profit.

\section{Research Methodology}

This research is descriptive and survival and regarded of adjective applied. The descriptive research consists of methods which aim to describe the existing conditions under study. Descriptive research is for aware of exist situation and merely carried out of get help the decision-making process. We can consider the behavioral sciences researches as the descriptive researches.

The descriptive-survey researches are used to consider the characteristics of a statistical population. To answer such a question like what kind of relationship is among the events? we apply this research (Sarmad and et al, 2003, p. 82).

Also the procedures of in this research are analogical-inductive. Analogical inference means that the theoretical frame work and the history for the research are developed through library, articles and the internet finds. Inductive inference means that the information collection through the primary data carried out to accept or reject the estimates and the results are generalized for the whole statistical population in the public sector accepted in TSE.

The population in this research consists of all the accepted companies in the TSE during 2005-2007.

Regarding the sampling method in the research is systematic omission (rule-out). Systematic sampling consists of units' selection based upon systematic method and consequently at nonrandom fashion. In this sampling, some conditions are taken into account in order to determine the sampling volume and the units of eligible statistical population are included in the sampling volume.

The members in the statistical population should have 4 characteristics:

1) Their fiscal year should be the end of year.

2) They shouldn't be a member of banks, credit institutes, financial brokers and financial investments.

3) Financial information required for the research between "2005-2007" should be prepared by TSE. 
4) Suspension period of the shares (stocks) transaction should be at least 3 months.

Based upon the definition of statistical population in the research, nearly 408 participants took part in this research. Subsequently, 330 participants were excluded from the research and finally 78 were chosen which it's shown on Table 1.

Insert Table 1 about here

In this research we applied the following methods:

1) Descriptive statistics: In order to describe the information gained in the research, we applied frequency, the least and the most average, standard deviation and the standard error deviation.

2) Inferential statistics: The following tests were used to test the estimates which, of course, had the reliability of $95 \%$. In other words, we can confirm the theory with an error degree of $(\alpha 0.05)$.

Otherwise, the zero hypotheses should be confirmed.

\subsection{Testing the research hypotheses}

The fist hypothesis: the announcement of the estimated profit each share causes a change in the rate and volume of the shares transactions. At first, data regarding shares transactions is classified 4 weeks before and after the announcement of the estimated profit for each share. Then their differences between the shares volume of transactions were calculated in before and after weeks of announcement. Having done his calculation, we can test the normality test.

Colmrograph-Smirnoph test is used to consider the normality of the paired samples' differences. When the normality of the differences is confirmed, paired T-test is used to test the hypotheses. If the abnormality is found, we use the non-parametric equivalent of the above-mentioned means Willcoxon signed-Ranks Test.

The second hypothesis: second estimate states: there is a relationship between the estimated profit and actual profit of each share.

At first, the data regarding the estimated profit and actual profit is classified. Then Kolmogorov-Smirnov test is used to consider the normality of data. Now the linearity or non-linearity of the relationship between the dependent and independent variables is tested. In order to do, linear regression is used the amount of coefficient, which A and B are calculated and the linearity function has determined. If the linearity of the relationship between the dependent-independent variables is confirmed, we refer to second test. Pearson's consistency test is used in this respect so as to prove the relationship between the dependent-independent variables.

\section{Results of the Study}

In the first hypothesis, share transaction volume is determined 4 weeks after/before the announcement of the estimated profit of each share which is considered as dependent and independent variables, respectively. The estimated profit of each share is also, considered as 
an interfering variable. In the second hypothesis, the estimated profit of each share and the actual profit of each share are considered as dependent and independent variables, respectively.

The description of the gathered data is as shown on Table 2.

Insert Table 2 about here

Insert Table 3 about here

\subsection{Test of normality}

We should be sure the normality or abnormality of the research variables, so that statistical testing will bear fruit. In the first estimate, normality test is conducted regarding the paired-samples differences in terms of shares transaction volume, and in the second hypostasis, normality test is carried out considering dependent- independent variables. As we-mentioned above, Kolmogrov-Smirnov test is used to test of normality. The summary of the test is as follows in Table4.

Insert Table 4 about here

Regarding that the Kolmogrov -Smirnov statistic value for the paired samples difference in the shares transaction volume is less at P.value 0/05; we conclude that it is not normal.

However, considering the fact that the Kolmogrov -Smirnov statistical value for the estimated profit and actual profit variables is more at P.value $\geq 0 / 05$, we can conclude that the above-mentioned variables are the normal distribution.

One of the reasons behind the abnormality of the paired samples in the first hypothesis is that the existing companies are heterogeneous in the statistical sample in terms of, field of activity, scope and transactions volume.

Findings of Research:

The first hypothesis

$$
\begin{aligned}
& \text { H0: } \mu \mathrm{x}=\mu \mathrm{y} \\
& \text { H1: } \mu \mathrm{x} / \mu \mathrm{y}
\end{aligned}
$$

The shares transaction volume (four weeks) after the announcement of the estimated profit for each share $=\mu x$

The shares transaction volume (four weeks) before the announcement of the estimated profit for each share $=\mu \mathrm{y}$

H0 (null) hypothesis: The announcement of estimated profit for each share doesn't cause a change in the rate and volume of the shares transactions.

H1 hypothesis: The announcement of estimated profit for each share doesn't cause a change in the rate and volume of the shares transactions.

As discussed, the normality of the paired-samples difference using Kolmogrov -Smirnov wasn't confirmed. Possibly, the reason behind the abnormality of the paired samples in the 
first hypothesis lies in the non-hetrogentry of the existing companies in the statistical sample in terms of scope, field of activity and the shares transaction volume points of view.

Now, we should use the non-parametric equivalent of the paired T-test (Wilcoxon signed - Ranks test). These tests will produce outputs as follows (shown in Table No. 5).

Insert Table 5

Statistic value of Wilcoxon signed-Ranks test is equal $Z=-5 / 177$. P-value of the above-mentioned test is zero means less than the standard value of $(0 / 05)$.

$(\mathrm{P}$ value $<0 / 05) \rightarrow \mathrm{RejH0} \quad \rightarrow \quad \mathrm{accH} 1 \quad \rightarrow \mu \mathrm{x} \neq \mu \mathrm{y}$

Then $\mathrm{H} 0$ is rejected and $\mathrm{H} 1$ is accepted. In other words, the announcement of the estimated profit for each share causes a change is confirmed.

The second hypothesis:

H0 (null) hypothesis:

There is no relationship between the estimated profit and the actual profit of per share.

H1 hypothesis: There is relationship between the estimated profit and the actual profit of per share.

Some points should be considered regarding using the regression:

Is the errors average zero?

Is the errors variance fixed?

Do the errors have the normal distribution?

Are the errors components independent from each other?

Then, first we should be sure accurate of the above-mentioned points. In the following table (Table 6), the 1st, 2nd and 3rd elements are considered.

Insert Table 6 about here

As it is considered, the errors average in the suitable regression model in the research is zero and the errors variance is fixed as well as the Kolmogrov -Smirnov statistic value is 1.136, and $\mathrm{P}$-value $=0 / 151>0 / 05$. Consequently approved, the have enjoy the normal distribution.

Durbin-Watson statistic value is use for the independency of the errors components. If this value is around 2, we can confirm that the error components in this model don't have meaningful consistency with each other and they have independent functions. So this value is equal to $1 / 805$ which is close to 2 , the independence of the errors components in the suitable (fitted) regression model is confirmed in this research.

The results gained from the regression can be trusted in which the fitted (suitable) regression model be meaningful totally. 
ANOVA table can confirm this meaning full that shown in Table 7.

Insert Table 7 about here

Since the $\mathrm{P}$ value in ANOVA is tended to zero and $\mathrm{P}$-value $=0<\mathrm{a}=0 / 05$, then we can most likely argue that the regression is meaningful.

The results based on the regression analyses have shown in Table 8 as follows:

Insert Table 8 about here

Regression line equation is as follows:

(The predicated profit per share) slope + width $=$ the actual profit for per share

$\mathrm{Y}=\mathrm{a}+\mathrm{bx}=\mathrm{Y}=282 / 805+0 / 716 \mathrm{x}$

The table 8 shows that since the calculated probability value of the data (P.value $=0 / 000)$ is less than meaningful level considered of the model $(\alpha=0 / 05)$, so the regression model is meaningful. Hence, we can confirm the linearity of the relationship between the dependent-independent variables.

Considering the fact that the normality of the research variables was established through Kolmogorov-Smirnov test and their normality confirmed, we use Pearson's correlation test to consider the relationship between the predicated profits of per share (independent variable) and actual profit of per share (dependent variable) table, shows this results:

Insert Table 9 about here

The above-mentioned data in table 9 shows that the P-vale $(0 / 000<0 / 05)$ is less than the standard level which confirms the insignificance of the error degree (rate) in the measurement and the correlation coefficient $(0 / 754)$ is, also, an indication of the relatively strong and positive relationship between both variables.

So, $\mathrm{H} 0$ hypothesis is rejected and $\mathrm{H} 1$ hypothesis is accepted. In other words, we can conclude that there is a relatively strong and meaningful relationship between the predicted profit of per profit and the actual profit of per share in the companies under study. Hence, the 2nd theory is established as:

$(\mathrm{P}$ value $<0 / 05) \rightarrow \mathrm{RejH} 0$

$\rightarrow$ accH1

$\rightarrow \mathrm{p} \neq 0$

The adjusted coefficient between the dependent and independent variables is 0.567 . In other words, 57 per cent variable change of the actual profit of per share is described through the predicted profit variable and the rest is described via variables other than the predicted profit of per share.

\section{Discussion and concluding}

In the present study, the first hypothesis results show that the announcement of the estimated profit per share causes a change in the rate and volume of the shares transaction. In other words, shares transaction volume increase or decreases due to announcement of the estimated 
profit of per share. If the estimated profit isn't satisfactory for the investors, the transaction volume decreases and vice versa.

The results based on the first hypothesis, shows that the announcement of the estimated profit of per share entails information content for investors and shareholders and they react them. In other words, this announcement acts as a reliable and valid source for the shareholders and investors who make decisions relying on it. Companies' management and other people who are in charge of estimating profit of per share should try to develop a better and exact information, other wise, any exaggeration regarding the estimation of profit will end up with the investors' dissatisfaction and incontinence. The result from the second hypothesis shows that there is a relationship between the estimated profit and the actual profit using linear regression test and correlation coefficient, it was proved that there is a relatively strong and positive relationship between both variables and the correlation rate $(r=0 / 954)$ shows, also, a relatively positive and strong relationship between both variables. This result confirms all of results gained from the first hypothesis. Based on the adjusted coefficient of 56/7, it can be said that $57 \%$ of the variable changes in per share is described through the predicted profit and the rest is explained through others variables.

\section{Recommendations}

The recommendations of this survey are as blow:

a) Applied suggestions

1) Preparation of necessary rules toward supporting investors from timely information companies.

2) Requiring the accepted companies in the Tehran Stock Exchange (TSE) to observe the rules and commitments with respect to giving information and identifying the situation various companies.

3) Providing the background for timely and accurate informing.

4) Regarding the information content of the estimated profit per share, the accepted companied in TSE required to announce their estimated profit on a specified date, so that the shareholders would make decisions over selling or holding their shares.

b) Suggestions for the future researches:

1) Considering the effect of estimated profit announcement on his financial supply of the accepted companies in TSE.

2) Considering the relationship between the charge percentages in the estimated profit per share with the change percentage in the shares price.

3) Carrying out the some research which is comprehensive from time scope and statistical sampling points of view.

4) Assessing the information content of the estimated profit of per share by the shareholders whom the direct interview or questionnaires are given in this regard. 


\section{Referencess}

Adel A. and Mansor Momeny. (1998). Statistic and its Application in Management, Tehran, Samt Publication, Second Edition.

Aghayi, Mohammad Ali Mokhtariyan and Omid ckeking. (2003) the Affective Factors on Deciding of Investors in Tehran Bond Burse, Accounting checkes, No. 36, pp: 25-29.

Baker, H.K. and J.A Haslem. (1974). The Impact of Investor Sociocomomic Character on Risk and Return Preferences, Journal of Business Research, Vol. 2, pp. 469-476.

Beker, H. K. And Haslem, J. A. (1974). The impact of investor sociocomomic character on Risk and return preferences, Journal of Business Reseach, Vol. 2, pp.469-476.

Eldon S. Hendriksen, Michael F. Van Breda. (2005). Accounting Theories, Irwin Professional Publication, $5^{\text {th }}$ Edition.

Gory Batachariya, Rechard janson. (1989). Statistics Concepts \& Methods, Jhon Willy Publication.

J. R. Hicks. (1946). Value and Capital, Oxford Clarendon Press.

Jahankhany, Ali. Saffariyan Amir. (2003). Reaction of Stock Market rather than Advertisement of Calculable Interest of Each Action in Listed firms in Tehran Stock Exchange, Financial Researches, Automn \& winter 2003, No.16, pp: 32-40.

James M .Patell. (1976). Corporate Forecast of Earning Per Share and Stock Behavior, Journal of Accounting Research, No. 3.

James M.Patell. (1976). Corporate Forecast of Eaening per Share and Stock Behavior, Journal of Accounting Research, No. 3.

Motiei Shobeyr. (2008). Checking of Relations between Mental Invest \& Indexes of Operations Assesses of Listed firms in Tehran Stock Exhange, Master Unpublish Desertaion, ,Azad university, Hamedan Barnch, Iran.

Norton Bedforf. (1971). The Income Concept Complex: Expansion or Decline, in Asset Valution, Robert Sterling Publication.

Prem Prakash and Alfred Rappaport. (1977). Information Inductance and its Significance for Accounting, Accounting, Organizations and Society, pp. 29-38.

Ray Ball and Philip Brown. (1968). An Empirical Evaluation of Accounting Income Number, Journal of Accounting Research, Autumn, pp. 159-178.

Sarmad zohreh,Bazargan Abas and Hejazi Elahe. (2003). Methods of Research in Behavior Sciences, Tehran, Agah publication.

Shabahang Reza. (2002). Accounting Theories, Tehran,center of Institute of Iranian Certified Public Accountants, First Edition.

Stephen P. Baginski. (1987). Information Transfer Associated with Earning, Journal of 
Accounting Research, Vol. 25, pp.196-213.

Warneryd, k.(2001). How People Value and Trade Stock, Stock Market Psychology, Available at : www.investopedia.com/university/broker/

Wayman, R. (2002). How to Evaluate the 'Quality' of EPS?, Available at: www.investopedia.com/university/

Table 1.

\begin{tabular}{|l|l|l|}
\hline No & No & Description (specification) \\
\hline 408 & & The members of statistical population \\
\hline & 76 & Companies for which the fiscal year isn't the end of year. \\
\hline & 41 & Companies which are involved in the activities that aren't the concern of the research \\
\hline & 49 & Companies which have not prepared the required information of the research \\
\hline & 164 & Companies in which the suspension period is more that 3 months \\
\hline 330 & & Companies excluded from the research \\
\hline 78 & & Sampling companies \\
\hline
\end{tabular}

Table 2. The description of the gathered data regarding the first hypothesis (per shares)

\begin{tabular}{|c|c|c|c|c|l|}
\hline $\begin{array}{c}\text { Standard } \\
\text { error average }\end{array}$ & $\begin{array}{c}\text { Standard } \\
\text { deviation }\end{array}$ & $\begin{array}{c}\text { Average } \\
\text { (mean) }\end{array}$ & $\begin{array}{c}\text { The most } \\
(\mathrm{max})\end{array}$ & number & Variable \\
\hline 356014 & 6764276 & 1724822 & 79739005 & 361 & $\begin{array}{l}\text { The shares transaction } \\
\text { volume 4 weeks } \\
\text { before the announcement }\end{array}$ \\
\hline $538522 / 7$ & 10226288 & 3230401 & 99245402 & 361 & $\begin{array}{l}\text { The share transaction } \\
\text { volume 4 weeks } \\
\text { after the announcement }\end{array}$ \\
\hline
\end{tabular}

Table 3. Description of the collected data regarding the second theory (Per Rial)

\begin{tabular}{|c|c|c|c|c|c|c|}
\hline $\begin{array}{c}\text { Standard } \\
\text { error average }\end{array}$ & $\begin{array}{c}\text { Standard } \\
\text { deviation }\end{array}$ & $\begin{array}{c}\text { Average } \\
\text { (mean) }\end{array}$ & $\begin{array}{c}\text { The most } \\
(\mathrm{max})\end{array}$ & $\begin{array}{c}\text { The least } \\
(\mathrm{min})\end{array}$ & Number & Variable \\
\hline $67 / 929$ & $1148 / 78$ & $1380 / 17$ & 7023 & 72 & 286 & $\begin{array}{c}\text { The predicted profit for } \\
\text { each share }\end{array}$ \\
\hline $64 / 484$ & $1090 / 52$ & $1270 / 32$ & 9204 & 77 & 286 & $\begin{array}{c}\text { The actual profit of } \\
\text { each share }\end{array}$ \\
\hline
\end{tabular}

Table 4. Asses of normality with using Kolmogrov -Smirnov Test

\begin{tabular}{|c|c|c|c|l|}
\hline Result & $\begin{array}{c}\text { Probability P. } \\
\text { value }\end{array}$ & $\begin{array}{c}\text { Statistical } \\
\text { value }\end{array}$ & Number & \multicolumn{1}{|c|}{ variable } \\
\hline Abnormal &.$/ 000$ & $6 / 461$ & 361 & $\begin{array}{l}\text { The difference of the paired samples in } \\
\text { the first hypothesis }\end{array}$ \\
\hline Abnormal &.$/ 813$ &.$/ 636$ & 286 & $\begin{array}{l}\text { Actual profit of each share in the second } \\
\text { hypothesis }\end{array}$ \\
\hline Abnormal &.$/ 456$ &.$/ 865$ & 286 & $\begin{array}{l}\text { The estimated profit of each share in the } \\
\text { second hypothesis }\end{array}$ \\
\hline
\end{tabular}


Table 5. Wilcoxon signed-Ranks Test

\begin{tabular}{|c|c|c|c|c|}
\hline $\begin{array}{c}\text { Sum } \\
\text { of } \\
\text { Ranks }\end{array}$ & $\begin{array}{c}\text { Mean } \\
\text { Rank }\end{array}$ & $\mathrm{N}$ & & \\
\hline 42720 & $\mathbf{1 8 6 . 5 5}$ & $229(\mathrm{a})$ & $\begin{array}{c}\text { Ranks } \\
\text { Ragative }\end{array}$ & $\mathrm{X}-\mathrm{Y}$ \\
\hline 22260 & $\mathbf{1 6 9 . 9 2}$ & $131(\mathrm{~b})$ & $\begin{array}{c}\text { Positive } \\
\text { Ranks }\end{array}$ & \\
\hline & & $1(\mathrm{c})$ & Ties & \\
\hline & & 361 & Total & \\
\hline
\end{tabular}

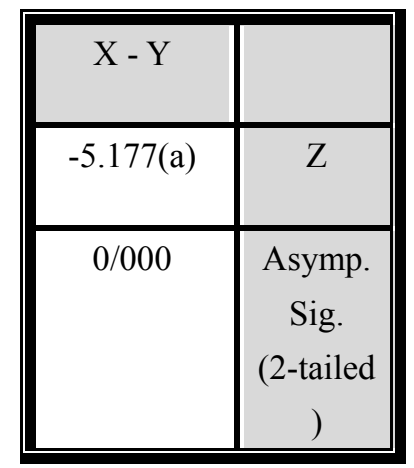
a. $\mathrm{X}<\mathrm{Y}$
b. $\quad X>Y$
c. $\mathrm{X}=\mathrm{Y}$

Table6. Calculation the errors average in the suitable regression model

\begin{tabular}{|l|l|l|}
\hline $\begin{array}{l}\text { Unstandardized } \\
\text { Residual }\end{array}$ & \multicolumn{2}{|l|}{} \\
\hline 286 & $\mathrm{~N}$ & Normal Parameters(a, b) \\
\hline 0.00 & Mean & \\
\hline $716 / 678$ & Std. Deviation & $\begin{array}{l}\text { Most } \\
\text { Differences }\end{array}$ \\
\hline 0.067 & Absolute & \\
\hline 0.061 & Positive & \\
\hline-0.067 & Negative & \\
\hline $1 / 136$ & Kolmogorov-Smirnov Z & \\
\hline 0.151 & Asymp. Sig. (2-tailed) & \\
\hline
\end{tabular}


Table 7. ANOVA analysis for determining of meaningful

\begin{tabular}{|c|c|c|c|c|c|c|}
\hline Sig. & F & Mean Square & df & Sum of Squares & & Model \\
\hline 0/000(a) & 373.561 & 192547004.846 & 1 & 192547005 & Regression & 1 \\
\hline & & 515436.061 & 284 & 146383841 & Residual & \\
\hline & & & 285 & 338930846 & Total & \\
\hline
\end{tabular}

Table 8 . The results Regression analysis

\begin{tabular}{|l|l|l|l|l|l|}
\hline Adjusted R2 & Durbin-Watson & $p$-Value & $\begin{array}{l}\text { Beta } \\
\text { value }\end{array}$ & coefficient & Variables \\
\hline \multirow{2}{*}{$0 / 567$} & \multirow{2}{*}{$0 / 805$} & $0 / 000$ & & $282 / 805$ & Fixed value \\
\cline { 5 - 6 } & & $0 / 754$ & & $0 / 916$ & $\begin{array}{l}\text { The predicted profit of per } \\
\text { share }\end{array}$ \\
\cline { 5 - 6 } & & $0 / 000$ & & &
\end{tabular}

Table 9. The assessment of the predicted profit and the actual profit of per share using Pearson correlation test

\begin{tabular}{|c|c|c|c|c|c|}
\hline $\begin{array}{c}\text { correlation rate } \\
(\mathrm{r})\end{array}$ & P-value & Number & Standard of error & Average (mean) & variables \\
\hline \multirow{2}{*}{$0 / 754$} & $0 / 000$ & 286 & $67 / 929$ & $1380 / 17$ & $\begin{array}{c}\text { The predicted profit per } \\
\text { share }\end{array}$ \\
\cline { 4 - 6 } & & & $64 / 484$ & $1270 / 32$ & The actual profit s \\
\hline
\end{tabular}

